\title{
Gradhiva
}

GRADHIV

Revue d'anthropologie et d'histoire des arts

$10 \mid 2009$

Présence africaine

\section{Allocution de Kojo Tovalou Houénou au Congrès de l'UNIA}

(Universal Negro Improvement Association, ou Ligue universelle pour la défense de la race noire) Harlem, New York, août 1924

\section{OpenEdition}

\section{Journals}

Édition électronique

URL : http://journals.openedition.org/gradhiva/1602

DOI : $10.4000 /$ gradhiva. 1602

ISSN : 1760-849X

Éditeur

Musée du quai Branly Jacques Chirac

Édition imprimée

Date de publication : 4 novembre 2009

Pagination : 204-205

ISBN : 978-2-35744-012-8

ISSN : 0764-8928

\section{Référence électronique}

"Allocution de Kojo Tovalou Houénou au Congrès de l'UNIA », Gradhiva [En ligne], 10 | 2009, mis en

ligne le 05 février 2010, consulté le 30 avril 2019. URL : http://journals.openedition.org/gradhiva/1602 ; DOI : 10.4000/gradhiva.1602 


\title{
Allocution de Kojo Tovalou Houénou au Congrès de l'UNIA
}

\author{
(Universal Negro Improvement Association, \\ ou Ligue universelle pour la défense de la race noire) \\ Harlem, New York, août 1924
}

\author{
Monsieur le Président, Messieurs les Délégués, \\ Messieurs les Députés, Mesdames, Messieurs,
}

Quand debout, vibrants, vous m'acclamiez tout à l'heure dans une ovation formidable, j'ai senti que ce n'est pas à moi que s'adressait cet hommage flatteur. C'est à la reine des martyrs, à la souffrante, à la douloureuse, mais à la toujours rayonnante et prestigieuse Afrique. Elle relève la tête après avoir été soumise pendant des siècles à un pillage éhonté, et après avoir subi des guerres désastreuses provoquées par des bandits européens dont le seul but était de se procurer des esclaves, crimes indélébiles commis sous le fallacieux prétexte de la civilisation et du dogme stupide de la suprématie de la race blanche. Consciente de son génie et de sa destinée, l'Afrique veut désormais se régénérer, elle aspire à se rédimer elle-même.

Vous fûtes les premiers et les seuls véritables artisans de la gigantesque prospérité de l'Amérique. Avec quelle rage et quelle férocité vous en avez été exclus! La société américaine aux prétentions démocratiques, mais dont l'impérialisme s'affirme de jour en jour, vous a bafoués, chassés, relégués comme des pestiférés. Elle vous abreuve tous les jours d'opprobre et d'humiliations. Las de tant d'épreuves imméritées, indignés d'un sort inique qui vous échut d'une patrie ingrate et hostile à votre adoption, désespérés de voir s'amender ceux qui osent maintenir encore la coutume ignominieuse et barbare du lynch et qui même quand les lois sont votées les violent impunément et cyniquement, vous vous êtes détournés avec horreur et dégoût d'un sol barbare pour jeter vos regards sur la terre d'Afrique qui fut votre berceau. Eh bien! je vous le dis au nom des millions d'Africains, nos cités sont prêtes à vous accueillir! Aucun gendarme anglais, français ou belge ne vous arrêtera au seuil. Vous êtes doublement des enfants de l'Afrique, par votre origine et par votre exil. Et puis, quelle leçon vous nous donnez! Comme tout s'éclaire et se précise dans les buts inavoués mais réels de la colonisation! Vous êtes les exemples vivants, la preuve irréfutable et définitive que l'Europe veut nous asservir. Dans le passé, l'esclave était un article d'exportation. Aujourd'hui, grâce à la colonisation, c'est le régime pour les Africains de l'esclavage à domicile. L'Européen s'est implanté chez nous pour se livrer au rapt, au vol, au viol et à l'abrutissement de nos congénères; il nous enlève nos propriétés, nos libertés civiles et nos libertés politiques.

La suprématie économique et politique qu'elle nous impose nous ravale et nous maintient au rang d'esclaves. Nous avons la volonté immuable d'être des peuples libres, ayant une civilisation propre qui régénérera le monde. Car l'orgueil, l'ambition, le matérialisme grossier, l'hypocrisie religieuse des peuples dits civilisés, ne sont plus qu'un objet d'écœurement et de dégoût pour le monde. D'ailleurs, quelle confiance pouvons-nous avoir désormais en ceux qui ont sacrifié dix-huit millions de jeunes gens pour le pétrole de Mossoul, la prévalence de la Royal Dutch sur la Standard Oil, le charbon de la Ruhr et le placement à des taux usuraires de l'or volé pendant les combats, l'anéantissement de la flotte et des colonies 
allemandes et la subjugation de leur bétail humain - naturellement des Nègres qui sont toujours monnaie d'échange : Donnez-moi l'arsenic, je vous cède les Nègres! Bon appétit, messieurs! D'ailleurs, soyez convaincus, Mesdames et Messieurs, que notre croisade sauvera les peuples d'Europe et d'Amérique de la pieuvre capitaliste. Ces pays fourniront les volontaires les plus zélés, car ils se rendent compte de jour en jour dans quel abîme leurs gouvernements les conduisent.

Votre association, $M$. le Président Marcus Garvey, est le sionisme de la race noire. Elle a l'avantage dans son radicalisme de préciser nettement le problème, de tracer la route large et lumineuse qui doit nous conduire au salut.

Je connais la vanité des formules oratoires et des écrits les mieux pensés et médités; loin de troubler nos bourreaux, ils composent d'autres chansons qui les bercent et chatouillent plus ou moins agréablement leurs oreilles. Il faut des décisions viriles et des actes énergiques. Vous êtes le tribun qui soulève les masses; rien de durable ne peut se fonder sans le peuple. Tout vient du peuple et tout va au peuple, et la voix du peuple est la voix de Dieu : «Vox populi, vox Dei. » L'Afrique, le plus vieux de tous les continents, peut bien disposer d'elle-même plus légitimement que ces fantômes de nations créés par les hallucinations wilsoniennes. La race noire qui la peuple et qui a essaimé sur tous les continents aspire à son unité. Elle veut se libérer du cancer européen qui la ronge et la gangrène depuis des siècles.

Avant d'être des Américains, des Anglais, des Français, des Belges, nous sommes des Nègres, nous sommes des Africains. On nous le fait bien sentir par les faveurs et les privilèges que les Caucasiens se taillent à nos dépens. Ils sont vraiment cocasses, ces tartuffes qui nous apprennent à mourir pour leur patrie pendant qu'ils ruinent la nôtre. Nous n'avons que faire d'ânonner sans cesse "Nos ancêtres les Gaulois». Nous n'avons aucune prétention à être de la race aryenne, ou, comme dit un homme d'esprit, de la race propre à rien. Nous avons une terre, un continent, une patrie : l'Afrique. La communauté de malheurs et de détresse a cimenté toutes les nations africaines. Nous sommes prêts à sacrifier notre vie pour cette patrie et à chasser de la terre d'Afrique l'Européen qui nous envoie à la boucherie de Verdun, nous réduit à l'état d'ilotes en Amérique et a l'impudence de nous asservir sur notre propre sol. La terre appartient à tous les hommes sans distinction de race; les Européens peuvent venir chez nous, comme nous avons le droit d'aller chez eux. Mais il faut qu'ils soient persuadés qu'ils sont des hôtes. Ce que nous ne voulons plus tolérer, c'est leur gouvernement qui nous gruge et nous gangrène. Nous sommes las des tuteurs qui ont dissipé les biens des mineurs et qui n'ont qu'un but, perpétuer leur tutelle. L'Afrique aux Africains, tel doit être désormais notre cri de ralliement sur toute la surface du globe. Aujourd'hui, le voile se déchire : «Je sais, je crois, je vois, je suis désabusé.» Croyez-moi, je vous parle d'après l'expérience et comme quelqu'un qui a vécu pendant vingt-cinq ans la civilisation européenne. Tout est préférable au gouvernement de l'étranger et surtout de l'Europe. Après ce que j'ai vu, j'aime mieux être régi par les lois des bêtes féroces; mieux vaut la société des tigres, des lions, des panthères et des serpents les plus venimeux. Il n'y a pas de pires bandits, de pires assassins que les Européens en Afrique. Latrones gentium. Raptores Orbis. Voilà ce que disent Salluste et Tacite des Romains. Les Européens sont des brigands qui dépouillent les peuples, ce sont les pillards de l'Univers. Vous êtes, M. le Président, l'artillerie lourde qui fera la trouée dans cette offensive que nous prenons. Mais permettezmoi de vous le rappeler : l'union fait la force. C'est par la solidarité de tous les congénères de notre Race, c'est par l'union que nous remporterons la victoire définitive'1.

\footnotetext{
-

1. Source : Émile Derlin Zinsou et Luc Zouménou, Kojo Tovalou Houénou, précurseur, 1887-1936 : pannégrisme et modernité, Paris, Maisonneuve et Larose, 2004 : 219-221.
} 